\title{
The Modeling of Wind Speed Based on Matlab
}

\author{
Zhilong Gao \\ Tianjin Key Laboratory of Information Sensing and Intelligent Control, Tianjin University of Technology and Education No.1310,Dagu \\ South Road, Hexi District, Tianjin 300222, China
}

\begin{abstract}
Wind is access to the source of the wind turbine energy, due to the nature of the wind speed, wind direction is changing, it must be considered all sorts of wind conditions in the running process may appear during build wind turbines model wind turbines, in this way can the result of the simulation can be reliable and perfect. Wind speed simulation is an important link in all kinds of wind power system simulation, wind speed model which can reflect the natural wind not only can provide the accurate source to the system ,but on the analysis of the influence of wind power generation system for grid voltage fluctuation. Wind speed combination model built up by using Matlab/Simulink, the simulation results show that the model could reflect the real wind speed ideal.
\end{abstract}

Keywords: wind power generation, Wind speed, Matlab/Simulink, Wind speed combination model.

\section{Introduction}

Into the 1990s,environment pollution and climate change has caught people's attention gradually. Wind power ,as a clean and renewable energy, has benn appreciated by many governments. With the rapid growth of wind power installed capacity, its dynamic performance and the impact on the grid has increasingly become a major topic in the field of the technology ${ }^{[1-3]}$.

In wind power simulation system, if the wind speed can reflect the actual wind conditions really, has a great influence on the performance of detection for the whole power generation system $^{[4]}$. Therefore, the accurate wind speed model become an important part of wind power system simulation. Figure 1 is the basic module diagram of wind turbine, it can be seen that the wind speed model is the source parameters for wind power research.

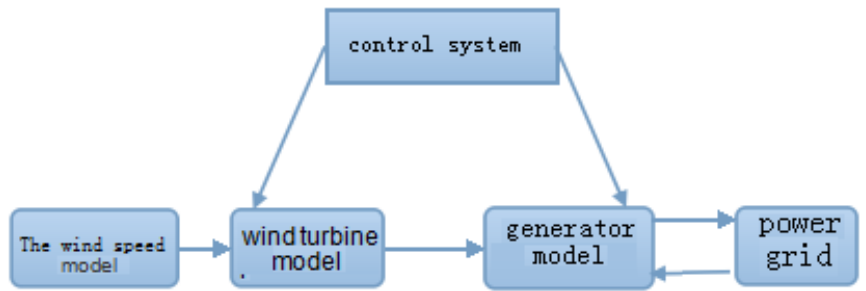

Figure 1: The basic module of wind turbine

\section{The Wind Speed Model}

To simulation the actual output characteristics of wind turbine in the laboratory without wind, the first thing is to establish the mathematical model of wind speed. In order to describe the characteristics of randomness and intermittent of wind, the natural wind speed can be divided into basic wind speed Vwb, fluctuating wind Vwn, gust Vwg and gradient wind Vwr4 parts based on the mathematical model of the combination of wind speed $^{[5-6]}$.

$$
V_{\mathrm{w}}=V_{w b}+V_{w n}+V_{w g}+V_{w r}
$$

Each part can be calculated easily, and shows the characteristics of wind speed in short time, test the performance of wind power generation system fully, especially when the change in wind speed Suddenly, the anti-interference of the whole system ${ }^{[7]}$.

\subsection{Basic wind speed}

The Basic wind speed in the whole process of operation of wind turbines, reflects the change of mean wind speed,and determines the size of rated power of wind turbines to the system as well.

$$
V_{\mathrm{wb}}=0.1+0.824 N^{1.505}
$$

In this type, $\mathrm{Vwb}$ is the average wind speed of n-tier wind $(\mathrm{m} / \mathrm{s})$; $\mathrm{N}$ is the series of the wind.

We can get the average wind speed if we have known the wind series $\mathrm{N}$. And we can get the maximum wind speed of $\mathrm{N}$ level wind, Vwbmax, its formula is

$$
V_{\text {wbmax }}=0.2+0.824 N^{1.505}+0.5 N^{0.56}
$$

The minimum wind speed of $\mathrm{N}$ level wind, Vwbmax,is

$$
V_{\text {wbmin }}=0.824 N^{1.505}-0.56
$$

Generally considered the basic wind speed does not change with time, thus can take constant, this paper take $8 \mathrm{~m} / \mathrm{s}$.

\subsection{Fluctuating wind speed}

To describe the stochastic characteristics of wind speed and changes in specified relative height, can use fluctuating wind to simulate. Fluctuating wind is random changes, when the atmosphere is relatively stable, can put the fluctuating wind speed as a stationary random process, with samples at one point for a long time observation to represent the statistical properties of fluctuating wind.

Fluctuating wind is the difference between combination of wind speed and average wind speed, gust of wind and gradient wind, as a result, the average time is 0 .

$$
V_{\mathrm{wn}}=\frac{1}{\Delta t} \int_{t 1}^{t 2} \mathrm{~V}_{\mathrm{wn}} d t=0
$$

Probability density function of fluctuating wind is very close to the gaussian distribution. So the probability density function of fluctuating wind can be expressed as. 


\section{International Journal of Science and Research (IJSR)}

ISSN (Online): 2319-7064

Index Copernicus Value (2013): 6.14 | Impact Factor (2014): 5.611

$$
p\left(V_{w n}\right)=\frac{1}{\sigma \sqrt{2 \pi}} \exp \left[-\frac{V_{w n}^{2}}{2 \sigma^{2}}\right]
$$

$\sigma$ is a R.M.S of Vwn.

\subsection{Turbulence intensity}

The turbulence intensity is used to describe the degree of changes, reflect the relative strength of a fluctuating wind. The turbulence intensity $\varepsilon$ is defined as the ratio of the square root value of fluctuating wind and the the average wind speed.

$$
\varepsilon=\frac{\sqrt{\left(u^{2}+V_{w n}^{2}+w^{2}\right) / 3}}{V_{w b}}
$$

$\mathrm{u}, \mathrm{vWN}, \mathrm{w}$ is the component of fluctuating wind at three orthogonal directions.

The three directions are defined as, $\mathrm{u}$ is the component of average wind speed at mean direction, also known as vertical turbulence intensity $\varepsilon \mathrm{u}$; VWN refers to a vertical component with $\mathrm{u}$ at the horizontal direction; $\mathrm{W}$ refers to the upright direction. In engineering, the vertical turbulence intensity $\varepsilon \mathrm{u}$ is main.

\subsection{Gust of wind}

To describe the characteristics of suddenly change of wind speed, Gust of wind are available, and wind speed with cosine characteristics within the time, in power system dynamic stability analysis, especially on the analysis of the influence of wind power generation system for grid voltage fluctuation, it is often use to assess the dynamic characteristics in the case of large wind speed change (characteristics of voltage fluctuation).

In the design, definit $G$ is gust factor. $G$ refers to the ratio of gust wind speed and the average wind speed, it is related to the intensity of the turbulence. The greater of the turbulence intensity is ,the larger of wind coefficient; the longer of the gust wind last, the smaller of G.

$$
\begin{gathered}
G(T)=1+0.42 \varepsilon u \ln \frac{3600}{T} \\
V_{\mathrm{wg}}=V_{\mathrm{wb}} G(T)
\end{gathered}
$$

$\mathrm{T}$ is the last time of gust wind.

\subsection{Gradient wind}

The gradient wind is used to describe the gradient change characteristics of wind speed.

$$
V_{\mathrm{wr}}= \begin{cases}0 & \mathrm{t}<T_{1 r} \text { 或 } t>T_{2 r}+T_{r} \\ R_{\max } \frac{t-T_{1 l}}{T_{2 r}-T_{1 r}} & T_{1 r} \leq t \leq T_{2 r} \\ R_{\max } & T_{2 r}<t \leq T_{2 r}+T_{r}\end{cases}
$$

Rmax is the maximum for gradient wind; T1r is the starting time; T2r is the over time; $\mathrm{Tr}$ is the keep time for gradient wind.
In conclusion, the mathematical model for wind speed can be established by(4),(5),(9)and(10).

$V_{\mathrm{w}}=V_{w b}+V_{w n}+V_{w g}+V_{w r}$

\subsection{Wind turbines modeling}

Wind power system modeling is the basis for wind turbine system to control and optimization , wind turbine is the most main components to accept, as well as the most basic and key components. The turbine simulation model can be established by following mathematical relationship.

$$
\left\{\begin{array}{l}
P_{t}=\frac{1}{2} \rho A V_{\mathrm{w}}{ }^{3} C_{p}=\frac{\pi}{2} \rho R^{3} V_{w}{ }^{3} C_{p} \\
\lambda=\frac{2 \pi n_{1} R}{60 V_{w}}=\frac{\omega_{t} R}{V_{w}} \\
T_{t}=\frac{P_{t}}{\omega_{t}}=\frac{\pi}{2} \rho R^{2} V_{w}{ }^{3} C_{p} \frac{1}{\omega_{t}}=C_{T} \frac{\rho \pi}{2} R^{3} V^{2} \\
C_{T}=\frac{C_{p}}{\lambda} \\
T_{t}-T_{g}=J \frac{d \omega_{t}}{d t} \\
C_{\mathrm{p}}(\lambda, \quad \beta)=(0.44-0.0167 \beta) \sin \left[\frac{\pi(\lambda-3)}{15-0.3 \beta}\right]-0.00184(\lambda-3) \beta
\end{array}\right.
$$

Pt output mechanical power for wind turbines, $\mathrm{kW}$; $\rho$ is air density, $\mathrm{kg} / \mathrm{m} 2$. $\mathrm{R}$ is radius for the rotor, $\mathrm{m}$; $\mathrm{Vw}$ is wind speed, $\mathrm{m} / \mathrm{s}$; $\mathrm{Cp}$ is wind energy utilization coefficient; $\lambda$ is tip speed ratio; $\omega \mathrm{t}$ is the rotor angular velocity omega, $\mathrm{rad} / \mathrm{s}$. Tt is wind turbines mechanical torque, $\mathrm{N} \cdot \mathrm{m}$; $\mathrm{CT}$ is the torque coefficient; Tg for generator load torque, $\mathrm{N} \cdot \mathrm{m}$; $\mathrm{J}$ is the equivalent moment of inertia for wind turbines, $\mathrm{kg} \bullet \mathrm{m} 2$.

\section{Modeling and simulation combination of wind speed and wind turbines by Matlab/Simulink}

Using Simulink to establish the mathematical model to simulation wind speed ${ }^{[8]}$. Figure 2 is the simulation waveform of mathematical model for the combination of wind speed .

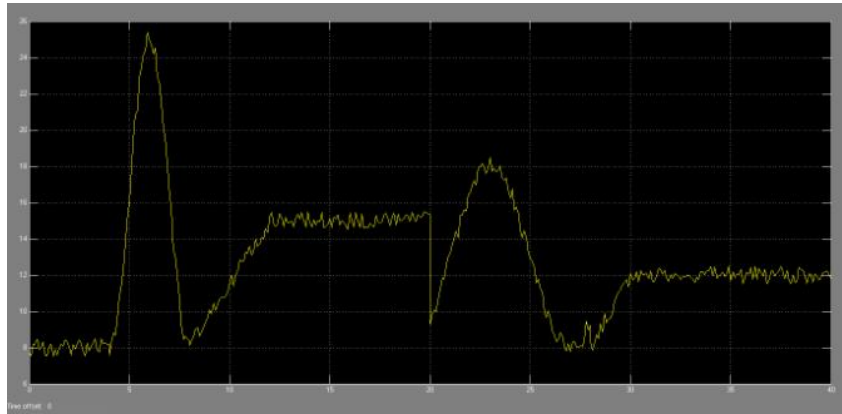

Figure 2: The combination of wind speed simulation curve

In wind turbines simulation model, the unit is fixed pitch, rotor radius is $\mathrm{R}=27.657 \mathrm{~m}$; Air density $\rho=1.225 \mathrm{~kg} / \mathrm{m} 2$. As shown in figure 3 is output curve which simulate actual wind 
turbine. Given the basic wind speed of $4 \mathrm{~m} / \mathrm{s}$, because of stochastic and the gradient component of the wind speed model, causing the change of wind speed within $3 \sim 5 \mathrm{~m} / \mathrm{s}$, power output and torque fluctuation.
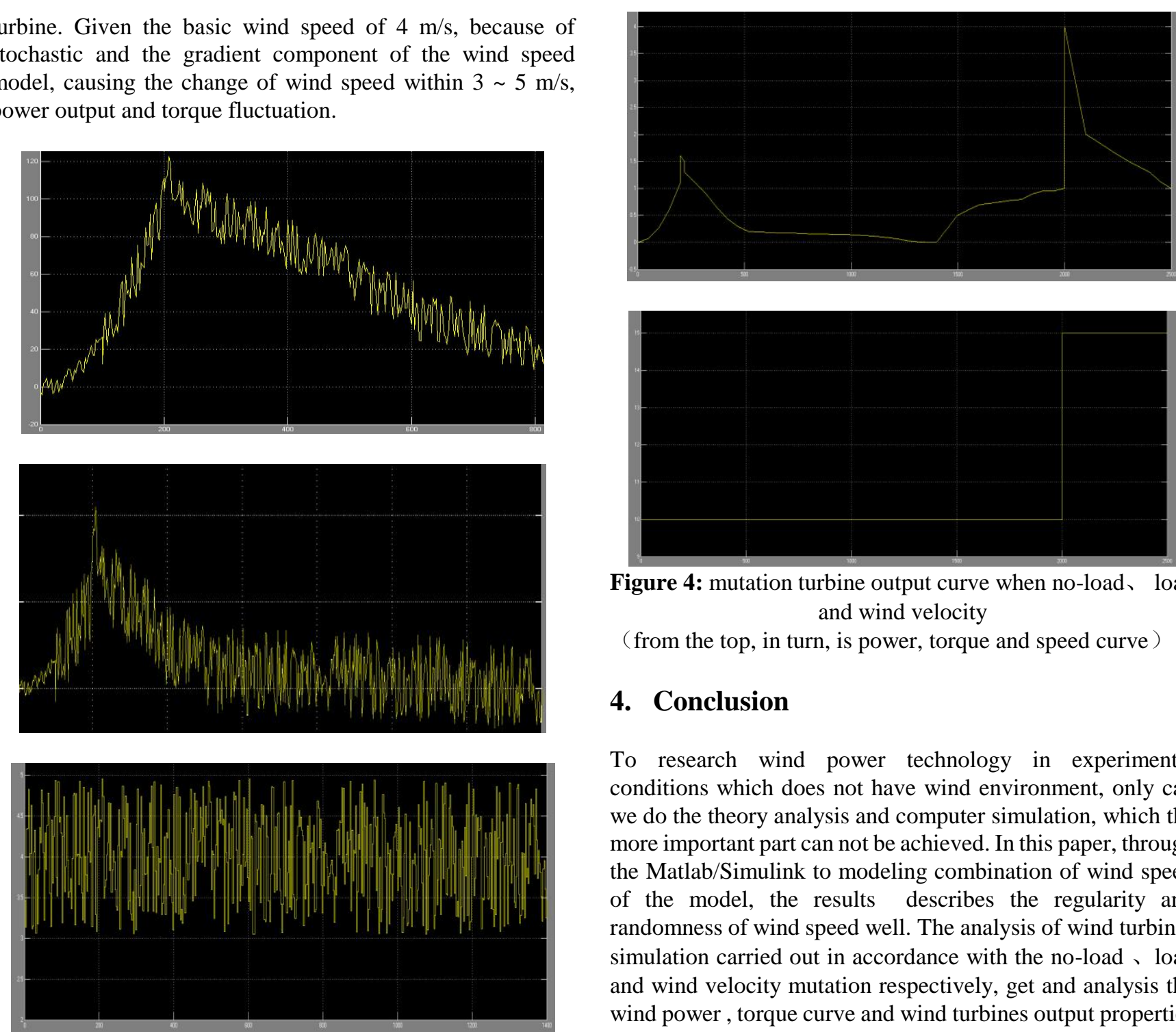

Figure 3: actual turbine output curve of wind speed (Note: from the top, in turn, is power, torque and speed curve)

To observation and analysis facilitately, definite the wind speed as basic wind which has given, $\mathrm{Vw}=10 \mathrm{~m} / \mathrm{s}$, as shown in figure 4. First make the turbine no-load, do not load the generator until the rotor speed is stability $(\mathrm{t}=1400 \mathrm{~s})$. When $\mathrm{t}$ $=2000 \mathrm{~s}$, the wind speed from $10 \mathrm{~m} / \mathrm{s}$ mutated into $15 \mathrm{~m} / \mathrm{s}$. From figure 4 you can see, when the wind speed increases, the turbine power output and torque increase, due to the load is constant, turbine output torque back to the original level.
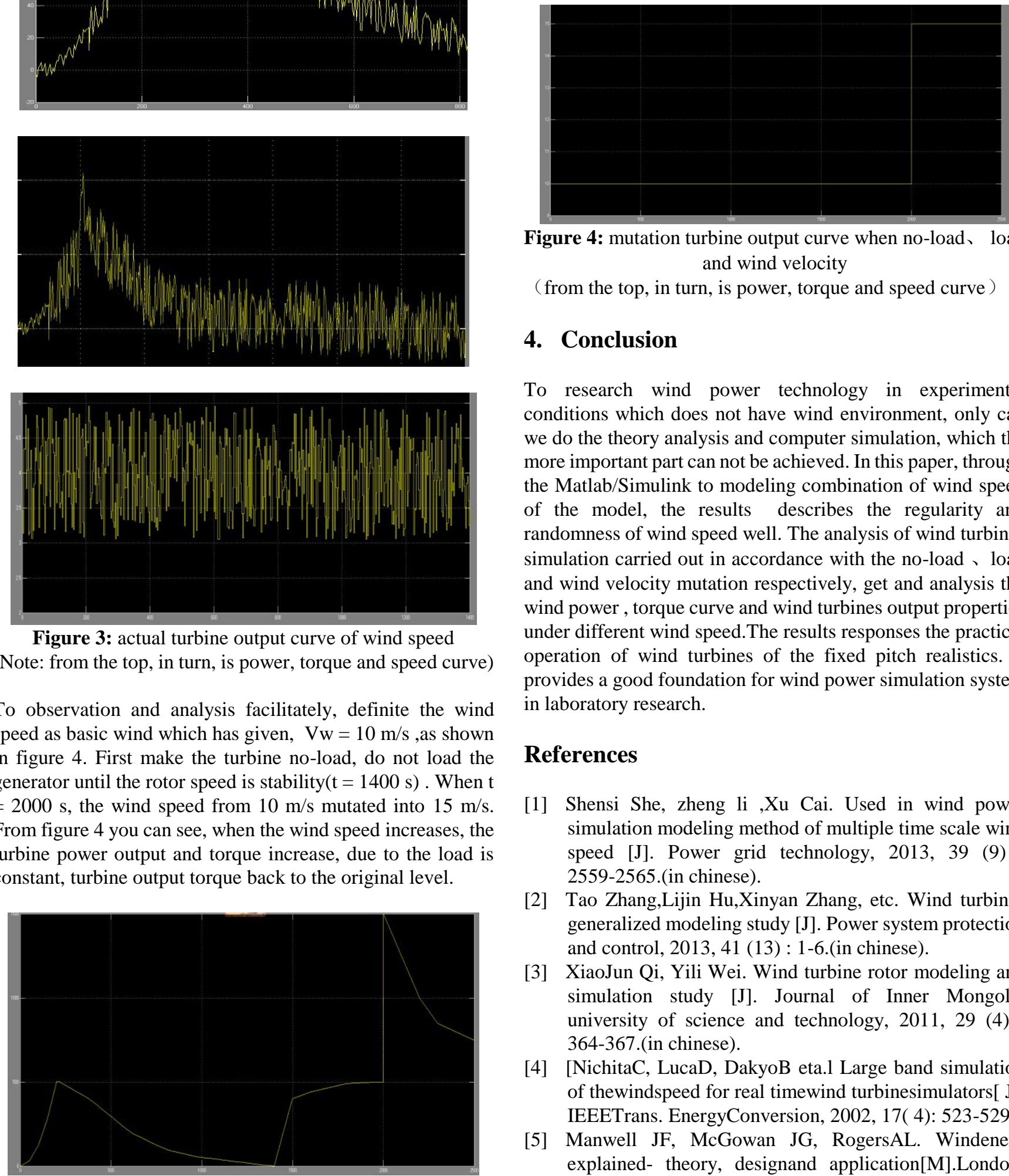

Figure 4: mutation turbine output curve when no-load、 load and wind velocity

( from the top, in turn, is power, torque and speed curve )

\section{Conclusion}

To research wind power technology in experimental conditions which does not have wind environment, only can we do the theory analysis and computer simulation, which the more important part can not be achieved. In this paper, through the Matlab/Simulink to modeling combination of wind speed of the model, the results describes the regularity and randomness of wind speed well. The analysis of wind turbines simulation carried out in accordance with the no-load 、 load and wind velocity mutation respectively, get and analysis the wind power , torque curve and wind turbines output properties under different wind speed.The results responses the practical operation of wind turbines of the fixed pitch realistics. It provides a good foundation for wind power simulation system in laboratory research.

\section{References}

[1] Shensi She, zheng li ,Xu Cai. Used in wind power simulation modeling method of multiple time scale wind speed [J]. Power grid technology, 2013, 39 (9) : 2559-2565.(in chinese).

[2] Tao Zhang,Lijin Hu,Xinyan Zhang, etc. Wind turbines generalized modeling study [J]. Power system protection and control, 2013, 41 (13) : 1-6.(in chinese).

[3] XiaoJun Qi, Yili Wei. Wind turbine rotor modeling and simulation study [J]. Journal of Inner Mongolia university of science and technology, 2011, 29 (4) : 364-367.(in chinese).

[4] [NichitaC, LucaD, DakyoB eta.l Large band simulation of thewindspeed for real timewind turbinesimulators[ $\mathrm{J}]$. IEEETrans. EnergyConversion, 2002, 17( 4): 523-529.

[5] Manwell JF, McGowan JG, RogersAL. Windenery explained- theory, designand application[M].London: JohnWiley\&SonsLtd, 2002. 
[6] LeieheadWE, Salle S, ReardonD. Role andobjectivesof control forwindturbines[ J]. IEEProc. C,1991, 138( 2): 135-148.

[7] Dongdong Li, Chen Chen. Wind power system dynamic simulation of the wind speed model [J]. Proceedings of the csee, 2005 (21) : 41-44.(in chinese).

[8] Yigang Kong, ZhixinWang. Wind turbine reliability modeling and analysis of dynamic process [J]. Journal of solar energy, 2008, 29 (6) : 652-656.(in chinese).

\section{Author Profile}

Zhilong Gao is reading the M.S. degrees in Automation and Electrical Engineering from Tianjin University of Technology and Education. 